\title{
Safety of Deep Enteroscopy and Capsule Endoscopy in LVAD Patients: Case Report and Literature Review
}

\author{
Wilson Tak-Yu Kwong ${ }^{\mathrm{a}, \mathrm{b}}$, Michelle Pearlman ${ }^{\mathrm{a}, \mathrm{c}}$, Denise Kalmaz ${ }^{\mathrm{a}, \mathrm{b}}$
}

\begin{abstract}
Patients with a left ventricular assist device (LVAD) have increased risk of gastrointestinal (GI) bleeding. They are prone to develop angiodysplasia of the small intestine, and have a higher risk of bleeding as these patients are all required to be on permanent therapeutic anticoagulation. Here we report a case of a critically ill 55-year-old male on pressors and inotropes with an LVAD, who successfully underwent an antegrade double balloon enteroscopy (DBE).
\end{abstract}

Keywords: Double balloon enteroscopy; Overtube-assisted enteroscopy; LVAD; Left ventricular assist device; GI bleeding

\section{Introduction}

Patients with a left ventricular assist device (LVAD) are at increased risk for gastrointestinal (GI) bleeding with $20 \%$ of patients experiencing at least one episode $[1,2]$. Approximately a quarter of these episodes of overt GI bleeding originate from the small intestine [3]. This is likely an underestimate as studies consistently show a high rate without identifiable bleeding source. Despite high rates of small intestinal bleeding, endoscopic evaluation of the small bowel with capsule endoscopy is rarely performed, while deep enteroscopy (spiral enteroscopy, single balloon enteroscopy, and double balloon enteroscopy) is even less so. The slow adoption of small bowel endoscopy in LVAD patients is likely related to uncertainty regarding safety of these procedures in a population with severe cardiac comorbidity with a new, evolving technology. We present an illustrative case with the second description of double

Manuscript accepted for publication September 18, 2015

aDepartment of Medicine, University of California San Diego, La Jolla, CA, USA

bDivision of Gastroenterology, University of California San Diego, La Jolla, CA, USA

${ }^{\mathrm{c} C}$ Corresponding Author: Michelle Pearlman, Department of Internal Medicine, University of California San Diego, 9500 Gilman Drive, La Jolla, CA 92093 0956, USA. Email: pearlmanmi@gmail.com

doi: http://dx.doi.org/10.14740/gr666w balloon enteroscopy (DBE) in an LVAD patient, and review the literature regarding the safety of deep enteroscopy and capsule endoscopy in patients with an LVAD.

\section{Case Report}

A 55-year-old male with dilated cardiomyopathy, atrial fibrillation, internal cardiac defibrillator, end-stage renal disease on hemodialysis, and iron deficiency anemia was transferred to our institution for LVAD placement. Esophagogastroduodenoscopy (EGD) and colonoscopy performed 4 months prior to LVAD placement to evaluate iron deficiency anemia were unremarkable. The patient remained hospitalized after HeartWare (Framingham, MA, USA) LVAD placement due to a complicated course including fungemia, ventricular arrhythmias, and aspiration pneumonia resulting in cardiac arrest and intubation from which he subsequently recovered. Three months after LVAD placement, the patient was transferred to the intensive care unit (ICU) for septic shock and required norepinephrine and dobutamine infusions for vasopressor and inotropic support. The following day, the patient developed maroon colored stools in the setting of aspirin and therapeutic anticoagulation with decrease in hemoglobin (Hgb) from 9 to $6 \mathrm{~g} / \mathrm{dL}$. He was transfused six units of red blood cells (RBCs). Urgent EGD and colonoscopy without bowel preparation demonstrated bilious fluid in the duodenum and blood throughout the terminal ileum and colon; however, the bleeding source could not be identified. Given suspicion for a small bowel source of bleeding, a PillcamSB (Given Imaging, Yoqneam, Israel) capsule study was performed. The patient continued to demonstrate signs of active GI bleeding and a tagged RBC scan was performed concurrently, revealing active blood loss from the small bowel. Mesenteric angiogram (Fig. 1) of the celiac and superior mesenteric arteries did not reveal extravasation of contrast. The capsule study demonstrated active bleeding in the proximal jejunum, although the bleeding source was obscured by blood (Fig. 2, Supplementary Video 1, www.gastrores.org). Push enteroscopy reached the proximal jejunum without signs of blood or a source of bleeding. The patient was subsequently intubated for worsening respiratory status and continued to require dobutamine and norepinephrine for hypotension. After discussion with cardiology, anesthesia, and cardiothoracic surgery, the decision was made to perform an- 


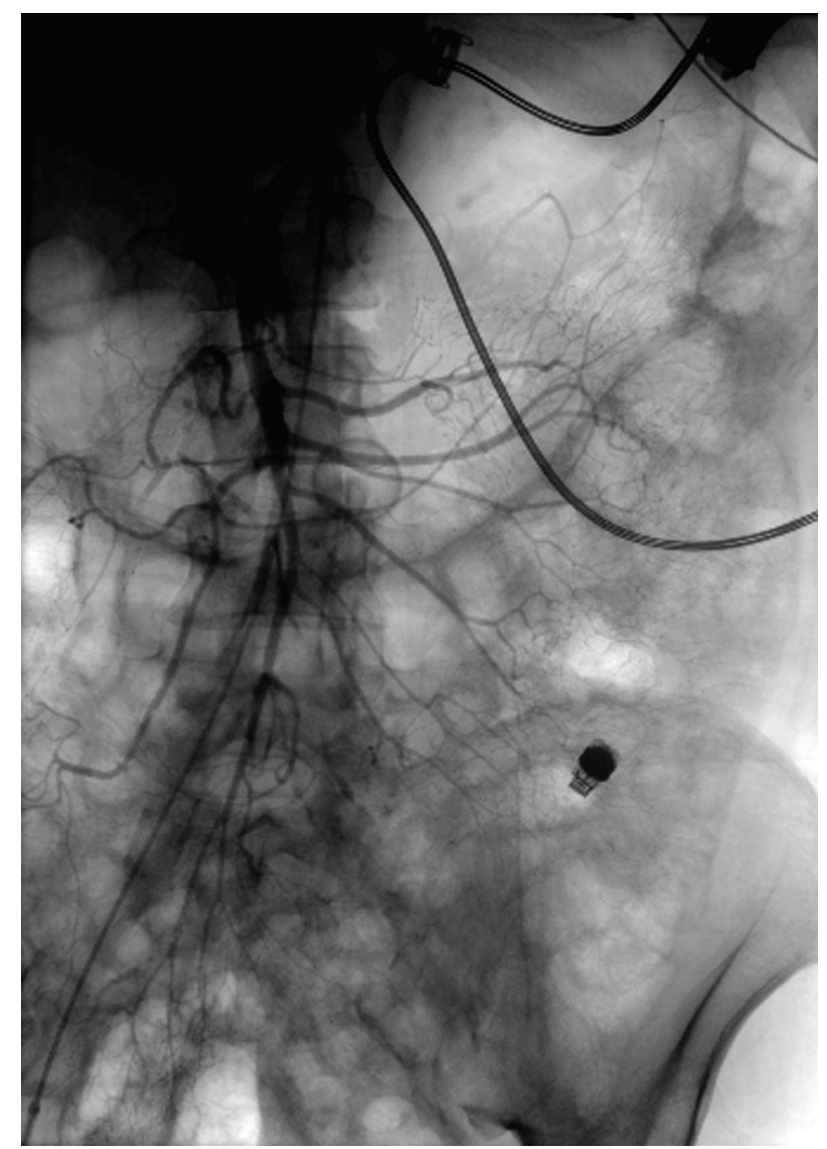

Figure 1. Angiogram of the superior mesenteric artery without extravasation of contrast. Notice the LVAD with driveline in the left upper quadrant and the PillcamSB in the left lower quadrant.

tegrade DBE given ongoing requirement for anticoagulation in setting of an LVAD. DBE was performed at the bedside in the cardiac ICU. The double balloon enteroscope (Fujinon, Tokyo, Japan) was advanced $250 \mathrm{~cm}$ past the ligament of Treitz without any signs of blood or potential bleeding source. The suspected bleeding source was a proximal jejunal Dieulafoy's lesion given the absence of mucosal lesions or angiodysplasia visualized on DBE. The patient tolerated the procedure without complication and his episode of bleeding ceased.

\section{Discussion}

Bleeding in patients with LVADs is likely to become a more frequently encountered problem given their increasing usage as destination therapy and bridge to transplantation. Evaluation of the small bowel appears to be of particular importance among LVAD patients given that there is increased small bowel angiodysplasia and up to $65 \%$ of patients have unidentified source of bleeding despite upper and lower endoscopy [4]. The high rates of unidentified sources of bleeding may be partly due to infrequent usage of capsule endoscopy and deep enteroscopy including spiral enteroscopy, single balloon enteroscopy (SBE), and DBE (Table 1) [2-15]. The infrequent usage of

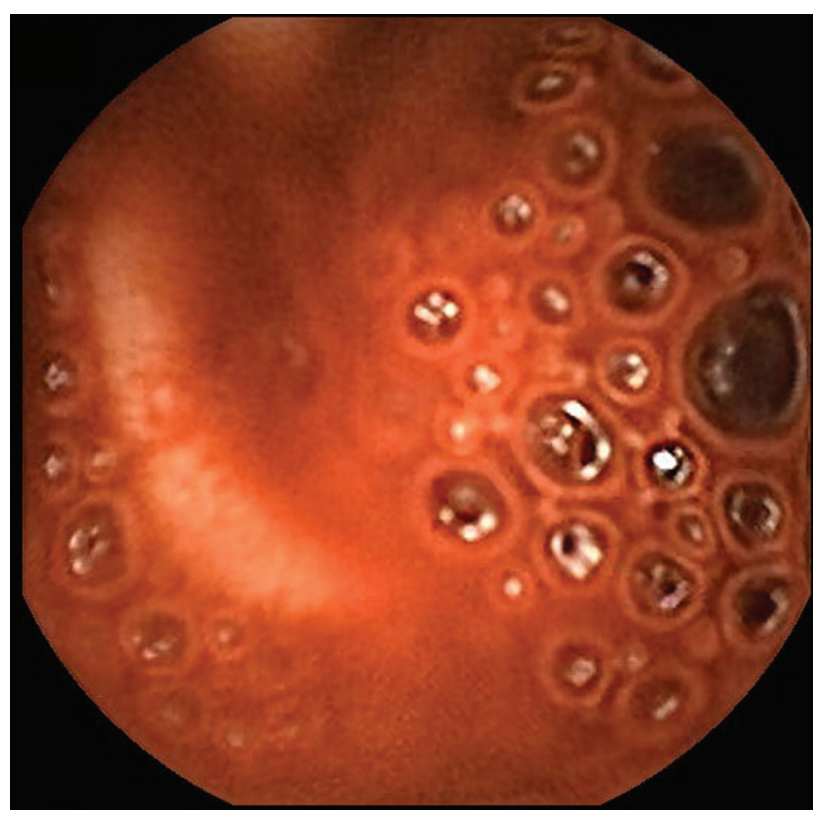

Figure 2. Capsule endoscopy demonstrates active bleeding in the proximal jejunum but blood obscures identification of the bleeding source.

these modalities to evaluate the small bowel may be attributed to uncertainty regarding the safety of these procedures in this patient population.

These procedures theoretically carry a higher risk compared to endoscopy and colonoscopy given the prolonged procedure and sedation time, repeated episodes of scope advancement and withdrawal with resultant pressure and mobilization of the small bowel in the upper abdomen. The LVAD driveline, which connects the LVAD to the external controller and power source, travels through the upper abdomen creating the potential of disrupting the driveline during deep enteroscopy. There is also concern that a capsule study may interfere with LVAD functioning and vice versa.

Review of the literature reveals that 62 capsule studies and 28 deep enteroscopies have been performed in LVAD patients. There has been one prior documented DBE performed in an LVAD patient [5] while three other studies did not distinguish spiral enteroscopy, SBE, and DBE $[3,6,7]$. The current case is the first DBE to be performed in a critically ill patient demonstrating it is possible to perform DBE safely even in the sickest of patients. Despite the limited number of reported LVAD patients undergoing capsule endoscopy and deep enteroscopy, these procedures appear to be quite safe in the LVAD population. The only major complication was a case of duodenal ulcer perforation after three attempts at cauterization. This complication is the result of attempted intervention rather than the enteroscopy itself. In addition, there are no reports of capsule endoscopy interfering with LVAD function, and only two reports of minimal interruptions in capsule image acquisition [8] which may not necessarily be the result of the LVAD's presence. There are also no reports to date of deep enteroscopy disrupting the LVAD circuit or the driveline. With increasing experience demonstrating safety, capsule endoscopy and bal- 
Table 1. Summary of Published Reports of Capsule Endoscopy and Small Bowel Enteroscopy in LVAD Patients

\begin{tabular}{|c|c|c|c|}
\hline Publication author, year & Capsule study & Enteroscopy & $\begin{array}{l}\text { Direct complications of capsule } \\
\text { study or enteroscopy }\end{array}$ \\
\hline Girelli et al, 2006 [9] & 1 & & None \\
\hline $\begin{array}{l}\text { Seow and Zimmerman, } \\
2006[10]\end{array}$ & 1 & One push & None \\
\hline Fenkel et al, 2007 [11] & 1 & & None \\
\hline Daas et al, 2008 [12] & 1 & One push & None \\
\hline Bechtel et al, 2010 [13] & 1 & & None \\
\hline Decker et al, 2010 [5] & 1 & One DBE & None \\
\hline Stern et al, 2010 [4] & 3 & & None \\
\hline Demirozu et al, 2011 [14] & & Two push & None \\
\hline Elmunzer et al, 2011 [6] & 13 & $\begin{array}{l}\text { Four SBE/DBE; three } \\
\text { push }\end{array}$ & None \\
\hline Huang et al, 2012 [15] & 1 & & None \\
\hline Kushnir et al, 2012 [2] & 5 & One push & $\begin{array}{l}\text { Duodenal ulcer perforation after } \\
\text { three episodes of electrocautery }\end{array}$ \\
\hline Harris et al, 2013 [8] & 14 & & $\begin{array}{l}\text { Two patients with brief interruptions } \\
(<2 \text { min) in capsule imaging }\end{array}$ \\
\hline Sarosiek et al, 2013 [7] & & Thirteen spiral/SBE/DBE & None \\
\hline Shrode et al, 2014 [3] & 20 & Ten SBE/DBE & None \\
\hline Total & 62 & $\begin{array}{l}\text { Eight push; } 28 \text { spiral/ } \\
\text { SBE/DBE }\end{array}$ & $\begin{array}{l}\text { One duodenal ulcer perforation } \\
\text { Two disruptions of capsule imaging }\end{array}$ \\
\hline
\end{tabular}

DBE: double balloon enteroscopy; min: minutes; push: push enteroscopy; SBE: single balloon enteroscopy; spiral: spiral enteroscopy.

loon assisted enteroscopy can become more widely utilized in the LVAD population which has particularly high rates of small bowel bleeding and a requirement for permanent anticoagulation.

\section{Conflicts of Interest}

The authors have no potential conflicts of interests to disclose.

\section{References}

1. Islam S, Cevik C, Madonna R, Frandah W, Islam E, Nugent $\mathrm{K}$. Left ventricular assist devices and gastrointestinal bleeding: a narrative review of case reports and case series. Clin Cardiol. 2013;36(4):190-200.

2. Kushnir VM, Sharma S, Ewald GA, Seccombe J, Novak E, Wang IW, Joseph SM, et al. Evaluation of GI bleeding after implantation of left ventricular assist device. Gastrointest Endosc. 2012;75(5):973-979.

3. Shrode CW, Draper KV, Huang RJ, Kennedy JL, Godsey AC, Morrison CC, Shami VM, et al. Significantly higher rates of gastrointestinal bleeding and thromboembolic events with left ventricular assist devices. Clin Gastroenterol Hepatol. 2014;12(9):1461-1467.
4. Stern DR, Kazam J, Edwards P, Maybaum S, Bello RA, D'Alessandro DA, Goldstein DJ. Increased incidence of gastrointestinal bleeding following implantation of the HeartMate II LVAD. J Card Surg. 2010;25(3):352-356.

5. Decker GA, Miller ED, Pasha SF, Harrison ME, Leighton JA. Deep enteroscopy in patients with left ventricular assist devices: practical and technical considerations. Endoscopy. 2010;42(Suppl 2):E194.

6. Elmunzer BJ, Padhya KT, Lewis JJ, Rangnekar AS, Saini SD, Eswaran SL, Scheiman JM, et al. Endoscopic findings and clinical outcomes in ventricular assist device recipients with gastrointestinal bleeding. Dig Dis Sci. 2011;56(11):3241-3246.

7. Sarosiek K, Bogar L, Conn MI, O'Hare B, Hirose H, Cavarocchi NC. An old problem with a new therapy: gastrointestinal bleeding in ventricular assist device patients and deep overtube-assisted enteroscopy. ASAIO J. 2013;59(4):384-389.

8. Harris LA, Hansel SL, Rajan E, Srivathsan K, Rea R, Crowell MD, Fleischer DE, et al. Capsule Endoscopy in Patients with Implantable Electromedical Devices is Safe. Gastroenterol Res Pract. 2013;2013:959234.

9. Girelli CM, Tartara P, Vitali E. Lack of reciprocal interference between capsule endoscope and left ventricular assist device. Endoscopy. 2006;38(1):94-95; discussion 95.

10. Seow CH, Zimmerman MJ. Capsule endoscopy in the de- 
tection of small-intestinal bleeding in patients supported by a nonpulsatile axial-flow Jarvik 2000 left ventricular assist device. Gastrointest Endosc. 2006;63(7):1087.

11. Fenkel JM, Grasso MA, Goldberg EM, Feller ED. Capsule endoscopy is safe in patients with pulsatile Novacor PC left ventricular assist device. Gastrointest Endosc. 2007;65(3):559-560; author reply 560.

12. Daas AY, Small MB, Pinkas H, Brady PG. Safety of conventional and wireless capsule endoscopy in patients supported with nonpulsatile axial flow Heart-Mate II left ventricular assist device. Gastrointest Endosc. 2008;68(2):379-382.

13. Bechtel JF, Wellhoner P, Charitos EI, Bucsky B, Morshu- is $\mathrm{M}$, Sievers HH. Localizing an occult gastrointestinal bleeding by wireless PillCam SB capsule videoendoscopy in a patient with the HeartMate II left ventricular assist device. J Thorac Cardiovasc Surg. 2010;139(4):e73-74.

14. Demirozu ZT, Radovancevic R, Hochman LF, Gregoric ID, Letsou GV, Kar B, Bogaev RC, et al. Arteriovenous malformation and gastrointestinal bleeding in patients with the HeartMate II left ventricular assist device. J Heart Lung Transplant. 2011;30(8):849-853.

15. Huang RJ, Wong RJ, Draper KV, Winter TA. De novo arteriovenous malformations following implantation of the HeartMate II left ventricular assist device. Endoscopy. 2012;44 Suppl 2 UCTN:E441. 